\title{
Dynamics of an infinite age-structured particle system
}

\author{
Dominika Jasinska ${ }^{1}$ and Yuri Kozitsky ${ }^{1}$ \\ ${ }^{1}$ Maria Curie-Sklodowska University
}

August 11, 2020

\begin{abstract}
The Markov evolution is studied of an infinite age-structured population of migrants arriving in and departing from a continuous habitat $\$ \mathrm{X} \backslash$ subseteq $\backslash$ mathds $\{\mathrm{R}\} \wedge \mathrm{d} \$$ - at random and independently of each other. Each population member is characterized by its age $\$ \mathrm{a} \backslash$ geq $0 \$$ (time of presence in the population) and location $\$ \mathrm{x} \backslash$ in $\mathrm{X} \$$. The population states are probability measures on the space of the corresponding marked configurations. The result of the paper is constructing the evolution $\$ \backslash$ mu_0 $\backslash$ to $\backslash$ mu_t $\$$ of such states by solving a standard Fokker-Planck equation for this models. We also found a stationary state $\$ \backslash$ mu $\$$ existing if the emigration rate is separated away from zero. It is then shown that $\$ \backslash$ mu_t $\$$ weakly converges to $\$ \backslash$ mu $\$$ as $\$$ t $\backslash$ to $+\backslash$ infty $\$$.
\end{abstract}

\section{Hosted file}

00age-sp.pdf available at https://authorea.com/users/350286/articles/475156-dynamics-of-aninfinite-age-structured-particle-system

\section{Hosted file}

00age-sp.tex available at https://authorea.com/users/350286/articles/475156-dynamics-of-aninfinite-age-structured-particle-system 